\title{
Right Sided Aortic Arch with Aberrant Left Subclavian Artery from Kommerell's Diverticulum, a Cause of Persistent Dysphagia in an Adult: A Case Report
}

\author{
Pradeep R Regmi ${ }^{1,3}$, Isha Amatya ${ }^{2}$, Bipula Kafle ${ }^{3}$, Prakash Kayastha ${ }^{4}$, Sharma Paudel ${ }^{4}$
}

\author{
Author(s) affiliation \\ 'Department of Radiology, University \\ Hospital of Ioannina, loannina, \\ Greece \\ ${ }^{2}$ Department of Community \\ Medicine, Kathmandu Medical \\ College, Duwakot, Bhaktapur, Nepal \\ ${ }^{3}$ Department of Radiology, Hospital \\ for Advanced Medicine and Surgery, \\ Dhumbarahi, Kathmandu, Nepal \\ ${ }^{4}$ Department of Radiology, \\ Maharajgunj Medical Campus, \\ Tribhuvan University Teaching \\ Hospital, Institute of Medicine, \\ Maharajgunj, Kathmandu, Nepal
}

\section{Corresponding author}

Prakash Kayastha, MBBS, MD

dr_prakash_kayastha@hotmail.com

\section{Submitted}

Sep 15, 2020

\section{Accepted}

Mar 29, 2021

\begin{abstract}
Congenital variations and anomalies of the aortic arch are important entity in vascular imaging. Most of them are asymptomatic. About 30-40\% presents with tracheo-oesophageal symptoms like dyspnea and dysphagia. A 27 year-old female presented with persistent dysphagia for 6 months duration and cause of persistent dysphagia was the right sided aortic arch with aberrant left subcalvian artery from Kommerell's diverticulum. The diagnosis was made through combination of chest X-Ray, echocardiography, non-ionic contrast swallow and Computed Tomography angiography. Non-invasive modalities (CT and MR Angiography) play an important role in diagnosis and pre-operative surgical planning providing relationship with the surrounding structures especially trachea and esophagus.
\end{abstract}

\section{Keywords}

Aortic arch, CT angiography, dysphagia, left subcalvian artery

\section{INTRODUCTION}

D ysphagia lusoria is the term used to describe the dysphagia secondary to vascular compression of the oesophagus. Only $30 \%$ of the vascular anomalies can result in trachea-oesophageal symptoms like dysphagia and dyspnea. ${ }^{1}$ The most common congenital anomaly of aortic arch is left sided aortic arch with aberrant right subclavian artery occurring 1 in 200 people. $^{2}$

\section{CASE PRESENTATION}

A 27 year young female presented with persistent dysphagia for solid foods, mild chest pain and feeling of something sticking on the chest for 6 months duration. There was no evidence of hematemesis or weight loss during this period. Clinical examination was unremarkable. After Chest X-Ray, echocardiography was done which revealed right sided aortic arch with abnormal branching pattern. Then, CT angiography of chest was advised for detail evaluation.

Chest X-Ray showed right sided aortic arch (absent aortic knob on left side) and trachea slightly deviated towards left side just above the carinal 


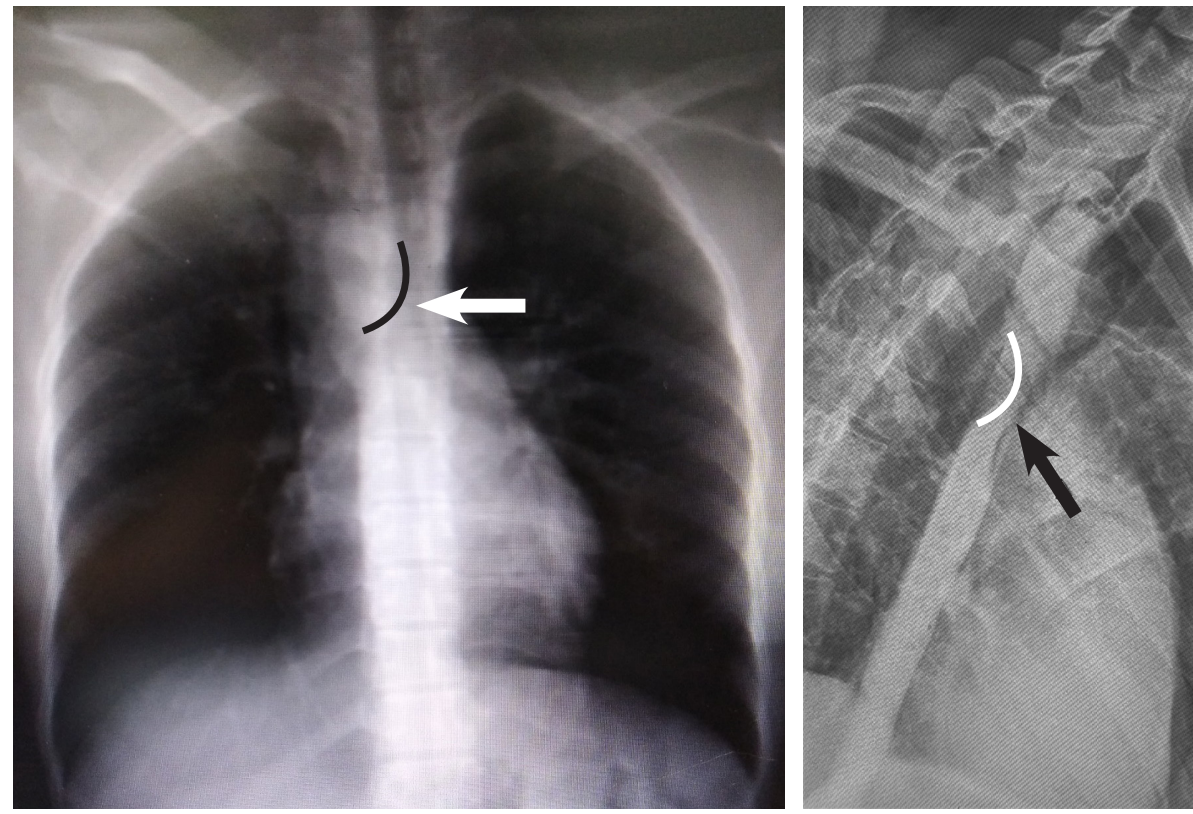

Fig 1a. Chest X-Ray PA view shows the right sided aortic arch with slight deviation of trachea just above the level of carina (black curve line). Lung parenchyma appear normal. Fig $1 b$. Left posterior oblique (LPO) non-ionic contrast swallow shows the smooth obtuse angled scalloping of oesophagus (posteriorly at the level of arrow shown by the curve white line) associated with proximal dilatation of the lumen.
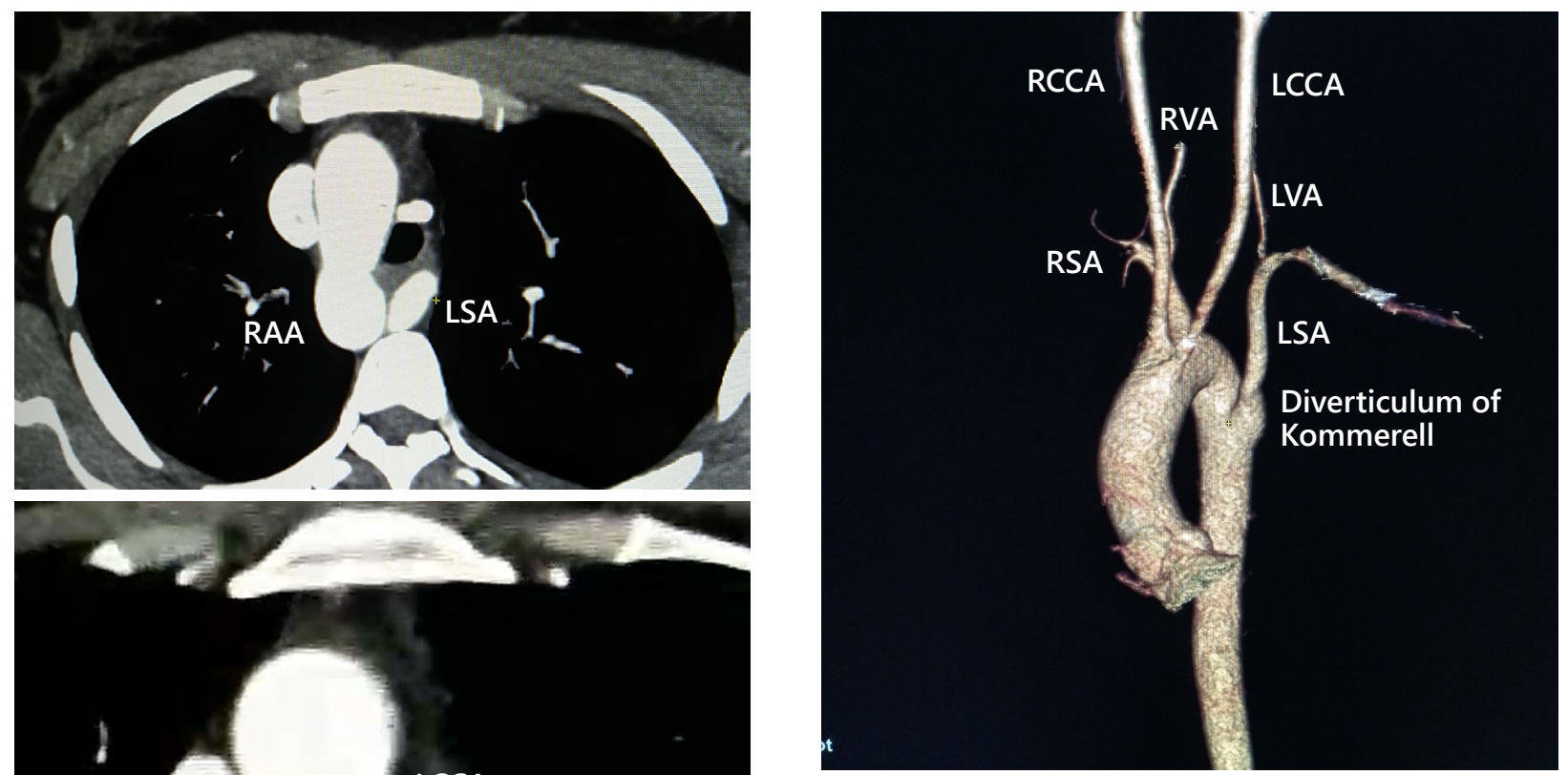

Fig 3. 3-D Volume rendering technique depicts the branches of aortic arch. (Image is rotated to show the branches clearly). LSA (left subclavian artery), RSA (right subclavian artery), RVA (right vertebral artery), LVA (left vertebral artery), LCCA (left common carotid artery) and RCCA (right common carotid artery).

bifurcation (Figure 1a). Left posterior oblique (LPO) non-ionic contrast swallow showed the narrowing of oesophagus with smooth obtuse angled scalloping (meaning external compression) of the lumen posteriorly. Pooling of contrast was seen in the oesophagus proximal to the narrowed part (Figure 1b). CT angiography showed aortic arch on the right side (Figure 2a). The origin of left subclavian artery was aberrant with focal dilatation in its origin known as diverticulum of kommerell. Lumen of oesophagus appeared narrow and is displaced of left subclavian artery (LSA) in prevertebral region posterior to trachea. Right sided aortic arch (RAA). Fig $2 b$. The origin of left subclavian artery from the aorta $(A)$ is dilated and is known as diverticulum of Kommerell (KD); Lumen of oesophagus (E) appear narrow and is displaced anteriorly; T (trachea) 
anteriorly (Figure 2b). The left subclavian artery (LSA) was seen traversing through prevertebral region posterior to trachea (Figure 3).

\section{DISCUSSION}

Primitive aorta during the development in third week of gestation consists of dorsal and ventral segments with six paired primitive arches between the dorsal and ventral aortic segments. Regression of some of the arches and development as well as persistence of the other arches forms the mature aortic arch. Edwards proposed the theoretical model for understanding the origin of the aortic arch and its variants. The most frequent anomaly of the aortic arch is aberrant right subclavian artery which appears in about $0.5 \%-1.8 \%$ of population. ${ }^{2,3}$

Right sided aortic arch (RAA) is the rare anomaly and has incidence of $0.1 \%$. According to the Edward model, there are three main subtypes; Type I-RAA with mirror image branching, type IIRAA with aberrant left subclavian artery and type III-RAA with isolated subclavian artery. Type II is the most common type. The aberrant left subclavian artery is the last branch and is coursing obliquely in retro-oesophageal region from the caudal right to cranial left. A bulbous configuration of the origin of an aberrant left subclavian artery is known as diverticulum of Kommerell. 4,5 Majority of the patients are asymptomatic and these anomalies are detected incidentally during adult age. However, $30 \%$ of patients presents with dysphagia similar to our case. The symptoms may be related due to compression of trachea or esophagus. ${ }^{1,2,6,7}$ Dysphagia lusoria likely to occur in case with diverticulum of kommerell. 8,9

Barium or other contrast swallow is not the regular modality of choice nowadays but is used for the screening purposes in a case of dysphagia. However, it can give the idea of site and nature of obstruction of oesophagus and proceed with other accurate modalities. Dating back to 1952, catheter guided angiography through puncturing the brachial artery was used for the accurate diagnosis of aberrant subclavian artery if suspected from barium swallow. ${ }^{10}$ Echocardiography is especially useful in children but its operator dependent and has its limitation in challenging cases. CT or MR are the modalities of choice for accurate depiction of the vascular anomalies and other causes of dysphagia. Despite the radiation dose, CT has its advantage of time in comparison with MR especially in paediatric population as it can be done even without sedation. The 3D volume rendering technique (VRT) is great advantageous tool for the evaluation of vascular anomalies of the aortic arch. ${ }^{4}$

\section{CONCLUSION}

Familiarity with the spectrum and imaging of congenital and common variations of the aortic arch is important for accurate diagnosis and guiding the proper management. Non-invasive imaging modalities (CT and MRI) play an important role in comprehensive evaluation of vascular anomalies and the relations with the surrounding structures to avoid inadvertent complications related to surgery and post-operative period.

\section{CONFLICT OF INTEREST}

None declared.

\section{REFERENCES}

1. Bennett AL, Cock C, Heddle R, et al. Dysphagia lusoria: a late onset presentation. World J Gastroenterol. 2013 Apr 21;19(15):2433.

2. Donnelly LF, Fleck RJ, Pacharn $P$, et al. Aberrant subclavian arteries: cross-sectional imaging findings in infants and children referred for evaluation of extrinsic airway compression. AJR Am J Roentgenol. 2002 May; 178(5):1269-74;

3. Cengiz A, Arslan S, Durmaz MS, et al. A Rare Cause of Persistent Dysphagia: Dysphagia Lusoria. Clin Med Img Lib 2016; 2:051.

4. Hanneman K, Newman B, Chan F. Congenital variants and anomalies of the aortic arch. Radiographics. 2017 Jan;37(1):3251.

5. Priya $S$, Thomas $R$, Nagpal $P$, et al. Congenital anomalies of the aortic arch. Cardiovasc Diagn Ther. 2018 Apr;8(Suppl 1):S26-S44.

6. Edwards JE. Anomalies of the derivatives of the aortic arch system. Med Clin North Am. 1948 Jan 1;32(4):925-49.

7. Sarv Priya RT, Nagpal P, Sharma A, et al. Congenital anomalies of the aortic arch. Cardiovasc Diagn Ther. 2018 Apr;8(Suppl 1):S26.

8. Jakanani GC, Adair W. Frequency of variations in aortic arch anatomy depicted on multidetector CT. Clin Radiol. 2010 Jun 1;65(6):481-7.

9. Mubarak MY, Kamarul AT, Noordini MD. Right-sided aortic arch with aberrant left subclavian artery from Kommerell's diverticulum. Iran J Radiol 2011 Sep;8(2):103.

10. Raphael RL, Schnabel Jr TG, Leopold SS. A new method for demonstrating an aberrant right subclavian artery. Radiology. 1952 Jan;58(1):89-9. 